\title{
Activity participation, episode duration and stop-making behavior of pilgrims in a religious event: An exploratory analysis
}

\author{
Ashish Verma ${ }^{a, *}$, Meghna Verma ${ }^{\text {b, }{ }^{* *}}$, Punyabeet Sarangi ${ }^{\mathrm{c},{ }^{* * *}}$, Vivek Yadav $^{\mathrm{c},{ }^{* * * *}}$, \\ Manoj $\mathrm{M}^{\mathrm{d} \text {,*** }}$ \\ ${ }^{\text {a }}$ Department of Civil Engineering and Robert Bosch Centre for Cyber-Physical Systems, Indian Institute of Science (IISc), Bangalore, 560012, \\ Karnataka, India \\ ${ }^{\mathrm{b}}$ Ramaiah Institute of Management, Bangalore, 560012, Karnataka, India \\ ${ }^{\mathrm{c}}$ Department of Civil Engineering, Indian Institute of Science, Bangalore, 560012, Karnataka, India \\ ${ }^{\mathrm{d}}$ Department of Civil Engineering, Indian Institute of Technology, Delhi, 110016, Hauz Khas New Delhi, India
}

\section{A R T I C L E I N F O}

\section{Keywords:}

Activity participation

Episode duration

Propensity of stops

Kumbh mela

Structural equation modeling (SEM)

Ordered logit model (OL)

\begin{abstract}
A B S T R A C T
Activity travel pattern of pilgrims in a religious setting is a complex process. Extant literature on religious tourism has taken minimal efforts in addressing such complexity, which has led to a paucity of information on preferred activity participation destinations and trip chain sequences of pilgrims. So, the present research objective is two-fold. First, to examine the causal effects of socio-demographics and daily local temperature on activity participation, trip chain type, and time allocation of individuals using structural equation modeling (SEM) that can help identify the dominant activity patterns. Second is to explore the impact of socio-demographic variables and activity patterns on the propensity of stop-making behavior using an ordered logit (OL) framework to better plan and manage the influx of flows. The primary data was collected using an activity-travel diary by taking the case study of the Kumbh Mela event, which is considered as the world's largest mass religious gathering, held at Ujjain, India, in 2016. From the results, it is observed that Males have a lower tendency to take multiple stops for primary religious activities and have simple trip chains. An increase in the members of a family visiting Kumbh decreases their overall time spent across various activities. As the mercury (temperature) rises, it reduces tourist's participation in recreational and discretionary activities. Individuals who participate in primary and secondary religious activities tend to spend more time at Kumbh as compared to individuals who primarily visit for recreational purposes. These empirical findings provide meaningful insights for managing large religious events.
\end{abstract}

\footnotetext{
* Corresponding author.

** Corresponding author.,

$* * *$ Corresponding author.

$* * * *$ Corresponding author.

$* * * * *$ Corresponding author.

E-mail addresses: ashishv@iisc.ac.in (A. Verma), meghnaverma75@gmail.com,meghna@msrim.org (M. Verma), punyabeet.sarangi287@gmail. com (P. Sarangi), vivekyadav2691@gmail.com (V. Yadav), manojm@civil.iitd.ac.in (M. M).
} 


\section{Introduction}

Religious tourism can be viewed as any travel that involves religious experience (Puşcaşu, 2015; Raj and Griffin, 2015). Given this definition, it can be said that all trips taken to religious sites and the activities that individuals engage themselves at these sites broadly define the religious tourism context from a transportation perspective. In fact, over the past few years, many researchers within the transportation field have explored the challenges faced by this sector. Firstly, any form of tourism (religious or recreational) is a perishable economic product due to the observed Spatio-temporal variances in the preference of travelers (Witt and Witt, 1995). These shifts in the behavior of travelers ${ }^{1}$ may have detrimental effects on the economic vitality of a country. Secondly, policymakers and transport planners face an arduous task of planning as well as maintaining a hassle-free religious event for visiting travelers as religious events are associated with traffic congestions, freight movements, etc. (Ahmed and Memish, 2019). Knowing the socio-demographic profiling of travelers and their motivation to visit and participate in religious activities can help planners improve and expand services for a steady flow of travelers. To address these challenges, as well as to have a better understanding of the tourism behavior, researchers have applied the well-defined activity-travel demand paradigm into the religious tourism sector. The popularity of these activity-based modeling frameworks can be attributed to the ease with which they incorporate the temporal and spatial constraints at the macro (household) and micro (individual) level of activity participation while providing a framework that is more viable and implementable in forecasting travel demand (Arentze and Timmermans, 2004; Bhat and Koppelman, 1999). Besides, these well-defined activity mechanisms provide acceptable inferences and a better understanding of the travel behavior of people that helps transport planners in framing policies to regulate the travel demand management smoothly.

Moreover, the interdependency between various keywords, namely joint travel, task and time allocation, episode frequency, trips, and tours, is well established in the extant literature on activity-travel demand modeling (Golob, 2003; Simma and Axhausen, 2001). This stream of literature is further enriched by various activity-based studies (Cheng et al., 2019; Liu et al., 2018; Manoj and Verma, 2015a) conducted in developing countries. These past studies based on activity paradigm have explored the interdependence between household demographics, individual attributes, in-home, and out-of-home activity participation, and travel behavior. However, only a handful of past studies in the activity domain have attempted to explicitly model the inherent relationship between pilgrim's activity participation and time allocation behavior in a massive conglomeration of pilgrims at a religious destination. This has led to a paucity of information on destination choices \& preferences; crowd movement \& management; and prioritizing \& planning activity participation due to temporal and spatial constraints in the context of events, festivals, and religious gatherings, etc. that are of global importance (Smallwood et al., 2012; Xia et al., 2011; Zoltan and McKercher, 2015). Notably, in a religious event, walking is the primary mode of movement for most of the between and within destination trips that are undertaken to participate in various activities inside the cordoned destination region ${ }^{2}$ for various religious fairs or festivals worldwide (Verma et al., 2018). With walking being a slow mode of travel, it induces both acceptable trip time and distance constraints. As a consequence, the choices and preferences of travelers in allocating time to various religious activities have to be carefully interpreted.

Furthermore, the propensity of taking stops during a home-based or non-home based tour by an individual has also been extensively researched in the past decade to understand the trip patterns and frequency of episodes undertaken by an individual (Chu, 2003; Timmermans et al., 2003). The findings of these studies reveal that travel patterns are mainly independent of spatial settings though some exceptions exist. However, unlike the traditional activity travel-based analysis where home-to-home is considered as the anchor point for a trip chain, in case of festivals and religious events, they have designated entry and exit points that make the trip chaining pattern more interesting and exciting to study but has garnered limited attention. In a religious event setting, pilgrims/visitors desire to participate in several activities in a cordoned destination region forces them to link their activities, resulting in complex trip chains. This interlinking of trips exhibited by individuals is stemmed due to a variety of external and internal factors (Smallwood et al., 2012; Xia et al., 2011). The external factors include socio-demographic characteristics (sex, age, income), weather condition (temperature, humidity etc.), socio-cultural factors (language, religion, culture) and service quality attributes (access to transport facilities, atm, etc.) while the internal factors include psychological aspects, behavioral traits like motivation, level of satisfaction, and perception towards individual safety and security (Alejziak, 2013; LaMondia et al., 2008). Thus, it can be seen that unlike the traditional home-based activity setting, a multitude of variables impacts the activity participation, time spent, and stop-making behavior of travelers visiting religious destinations. However, the current work is mainly concerned with the causal effects of socio-demographic variables on activity participation, time spent, and the stop-making behavior of travelers visiting a religious site.

Based on the above discussions, the present study has tried to address the existing gaps in the religious tourism sector with the following objectives: i) examine the interdependencies between socio-demographics, climatic conditions, religious activity participation, and travel pattern (that includes total time spent and trip chain type) of individuals using structural equation model (SEM). ii) exploring the impact of socio-demographic variables, climatic conditions, and religious activity participation on the propensity of stopmaking behavior using an ordered logit (OL) model to identify the dominant activity patterns of tourists/pilgrims at a religious event. Here, both the proposed empirical approaches are estimated independently by taking the case study of Kumbh Mela, which was held at Ujjain, India, from April 22, 2016 to May 21, 2016. The reason behind carrying out the study at Kumbh Mela is that it is considered as the largest human congregation on Earth and experiences footfall from all over the world. The event represents a fascinating amalgam

\footnotetext{
${ }^{1}$ For the ease of convenience, the terminologies 'travelers', 'tourists', 'visitors' and 'pilgrims' used in the present study are synonymous of each other and must not be interpreted differently. They refer to an individual visiting Kumbh Mela.

2 A cordoned destination region is perceived as an area encircled with discrete physical \& management boundaries with closeness to resources (i. e., attraction or recreation sites) such that an individual can visit the entire area in a day's time (WTO, 2007).
} 
of religious and social activities, and recreational elements assembled in a short span with limited space (Maclean, 2008).

The remaining paper is divided into six sections. Section 2 briefly describes the extant studies on activity participation, time allocation, and trip chaining behavior from a methodological perspective. Section 3 and 4 respectively discuss the specification and theoretical foundation behind the empirical frameworks undertaken in the present paper. This is followed by section 5 , which contains a description of the study area and data (exploratory analysis of exogenous and endogenous variables). The penultimate section (Section 6) elaborately interprets the causal effects and empirical findings of the models. The final section concludes with the salient findings and scope of future research.

\section{Literature review}

Understanding tourist/visitor's time spent on various activities and trip-chain pattern at religious events have been gaining interest among researchers as it impacts the planning and regulation of policies at these events. Thus, section 2.1 presents a brief review of past studies that have explicitly used structural equation modeling (SEM) to model time spent by individuals in various religious activities, and section 2.2 discusses past studies that have used ordered logit (OL) model to study the stop-making propensity of individuals.

\subsection{Modeling time allocation and trip chaining pattern of individuals using SEM framework}

Contemporary studies on household travel behavior have established a firm relationship between activity participation, time allocation, trip chaining pattern, and socio-demographic (Golob, 2000; Golob and McNally, 1997; Lu and Pas, 1997; Simma and Axhausen, 2001). While, activity participation may be defined as the need to perform an activity that motivates an individual to take an out-of-home trip, distributed over space and time (Kitamura, 1988) trip chaining, on the other hand, may be defined as a tour with the home as the starting and ending point and consists of multiple out-of-home activities as anchor points (Primerano et al., 2008). In this regard, Golob and colleagues pioneered the SEM technique in transportation planning to understand the association between activity participation, trip chain, and time spent across socio-demographic categories. After which, in the last decade SEM models have been widely used to study the causal effect of individual characteristics and household structure on activity participation and travel pattern choices (Chen and Akar, 2017; Kuppam and Pendyala, 2001; Pitombo et al., 2011; Whitehead-Frei and Kockelman, 2010). Among these studies, Kuppam and Pendyala (2001) focused on understanding the structural relationships between commuter's demographics, activity patterns, trip generations, and trip chaining. The results of their study proved that there exists a strong relationship between demographics, activity engagement, and travel behavior. Besides, Whitehead-Frei and Kockelman (2010), in their study of American time use using SEM, focused mainly on the in-home and out-of-home activity-participation of children and women. Similar studies conducted by Pitombo et al. (2011) and Chen and Akar (2017) observed that family income, household head, gender as well as car ownership has a strong influence on activity participation, joint travel, and origin/destination choices. Further, in affirmation to the studies conducted in developed countries, studies conducted in developing nations such as research works by Cheng et al. (2019) in the Chinese context and works by Manoj and Verma (2017, 2015b) in the Indian context also concluded that the aforementioned variables strongly influence the travel behavior and activity participation of household members.

However, most of the extant literature that have modeled time allocation and trip chaining pattern of individuals using the SEM framework has primarily focused on the home-based tours. Besides, scholarly works in the field of religious destination or leisure tourism are either obsessed with eliciting the behavioral traits of visitors at a tourist/religious destination or are focused on understanding the decision-making process of a tourist in choosing a destination. As per the author's knowledge, very few peer-reviewed studies have touched upon the activity participation and travel behavior of visitor's at a religious destination from a transport planning perspective. Summarizing these studies, it can be said that the movement of visitors between various activity focal points at a religious/tourist destination can be complex (Xia et al., 2011). Such complexity stems from the numerous travel routes available to an individual (Gayathri et al., 2017), the spatial distribution of activity attractions (Lew and McKercher, 2002) and demographics of the visitors (Xia et al., 2011). Hence, these interesting observations, combined with the revival of religious sites/tourism destinations across the globe, presents a unique challenge of exploring the activity participation and travel behavior of visitors at these destinations.

\subsection{Ordered logit model}

The number of stops taken by an individual during a tour is generally modeled as an ordered variable in the literature (Daisy et al., 2018). Therefore, ordered logit (OL) models have been utilized to not only understand the travel behavior of people through household surveys (Bhat and Srinivasan, 2005; Nurul Habib and Miller, 2007; Daisy et al., 2018) but also tourist behavior at religious events/festival destinations (Kemperman et al., 2003; Yang et al., 2011). The OL approach predicts the preferences of persons in undertaking an ordered number of stops in a temporally constrained activity set up (Nurul Habib and Miller, 2007). In the context of home-based tour, frequency of activity episodes rather than total stops during a tour is given as the input in the ordered set up (Bhat and Zhao, 2002; Bhat and Srinivasan, 2005; Nurul Habib and Miller, 2007; Arentze et al., 2011). Many researchers have found a variety of factors, including socio-demographics, land use density, work schedule, availability of transportation services, work duration, activity levels etc., affecting the propensity of making stops. Bhat (1997) formulated a joint model of work mode choice and non-work stops for commutes to work. The model identified socio-demographic variables, work duration and overall activity at the household level to be significantly affecting the stop making propensity of workers. In a similar study, Bhat (1999) also found that socio-demographics, retail employment density and work-related characteristics significantly impacts the evening commute stop making behavior of workers using the 1990 San Francisco Bay Area Household Survey data. Krizek (2003) looked at the effect of 
accessibility in neighborhood of Central Puget Sound regions (Seattle, Washington) on tour types and stops and found that households in neighborhoods with higher level of access are prone to make few stops for work and maintenance tours as residents tend to make much simple tours (leave and back home). Among research works on similar lines in European context, Maat and Timmermans (2006) found that high density areas cause more complex trip chains resulting in a greater number of stops per tour. Apart from socio-demographics and built environment in the previous studies, Cao et al. (2008) also identified that attitudes and work-related attributes influence the stop making behavior of workers. Kun et al. (2009) used land use density, work schedule, transportation services and socio-demographics of workers in Beijing to predict the number of stops at five different time periods of the day using stop frequency models. Doherty and Mohammadian (2011) used ordered response choice models in predicting the activity schedules of out-of-home tours as function of activity types and its characteristics. However, despite all these methodological advancements to model the stop making propensity in the home-based setup, very few of these advanced models have seen an application in religious/tourism activities. Moreover, from the handful of studies (Kemperman et al., 2003; Yang et al., 2011), which the authors could gather, on modeling tourism activity stops, the findings revealed that waiting time in queues, activity distance locations, visitor characteristics affect their stop making behavior. However, these studies analyzed tourism set up, and none of the existing literature has tried to explore it in a religious context, which makes it more appalling to model the religious activity episodes of pilgrims.

The above literature is not comprehensive and exhaustive. As can be inferred from the above paragraphs of section 2, most of the past studies have limited themselves to formulate empirical approaches to study the out-of-home activity participation and travel behavior of individuals using household-level surveys in developed countries. However, there is a lack of literature on the travel behavior of tourists in a religious gathering. Evidence from past studies have also indicated that the travel behavior of pilgrims in a religious setting is entirely different from that of contemporary household travel behavior. For example, an empirical study conducted by Masiero and Zoltan (2013) found that young people mostly travel to participate in recreational and cultural activity hotspots and are more likely to move widely through a destination. On the other hand, families traveling to these destinations show restricted but more intense movement patterns. Hence, a better understanding of the travel patterns of the heterogeneous participants at a religious event like Kumbh Mela helps in formulating effective transportation policies and adequately manage the logistics issues.

\section{Model specification}

This section describes the formation of empirical frameworks used in the present study.

\subsection{SEM specification}

Based on the activity-travel behavior theory and literature review, a structural equation modeling (SEM) framework was laid out, as shown in Fig. 1. Based on the first objective and as shown in the figure, it was hypothesized that socio-demographic characteristics and external climatic conditions (Temperature expressed in degree Celsius) influence travel patterns (includes the total time spent and trip chain type) of travelers visiting Kumbh Mela mediated by activity participation. In doing so, the indirect effects of sociodemographics and climatic conditions on travel patterns occur as well channeled via activity participation. The total effects are then calculated by adding up the direct and indirect effects. Here, activity participation is captured by dummy variables with ' 1 ' indicating an individual's decision to participate in an activity, namely Primary Religious, Secondary Religious, and Recreational activities, and ' 0 ' indicates non-participation. As can be seen, all the variables that are of concern in the present study are directly observed (manifest variables). Hence, the results are based on a series of simultaneously estimated structural (linear regression) equations.

A brief description of the list of sub-activities included under each main activity type in a religious setting is shown in Table 1. Classification of sub-activities into these four main types of activity is done based on the review of earlier studies (Buzinde et al., 2014; Raj and Griffin, 2015) and to the best understanding of the authors about a religious event. Here, discretionary activities were not considered as a mediation variable in the SEM framework as discretionary activities are something individuals must perform out of simple necessity, that is, an individual would probably not participate in Kumbh Mela just to perform discretionary activities. Primary religious activities include offering prayer, taking a holy dip, visiting temples, and visiting camps/akharas. These activities are the primary reasons for the pilgrims to attend Kumbh Mela. The other religious activities like listening to preaching, reading the holy book, meeting Naga sadhus (saints), etc. are believed to be a consequence of participating in primary religious activity and hence are considered as secondary religious activities. Performing Yoga, Shopping at Kumbh Mela, Cleaning ghats ${ }^{3}$, etc. are the activities that are included under recreational activities. Discretionary activities include eating, using comfort stations, resting due to fatigue etc. These activities are secondary in nature but part and parcel of any pilgrim's travel.

The travel pattern of visitors is defined by total time spent by an individual in various activities (Primary Religious, Secondary Religious, and Recreational) at Kumbh on the day of the survey and his/her trip chain type. Here, total time spent is taken as a continuous variable and is entered into the model in natural logarithm units (base 10) while trip chain type is a binary outcome variable with ' 0 ' indicating 'Simple Chain' and ' 1 ' indicating 'Complex Chain'. As the objective of trip-chain classification was to identify complicated and uncomplicated tours, those trip-chains that have a single religious or recreational activity were grouped as 'Simple' (or Uncomplicated), and 'Complex' (or Complicated) trip-chains were those with multiple religious or recreational activities.

${ }^{3}$ a flight of steps leading down to a river. 


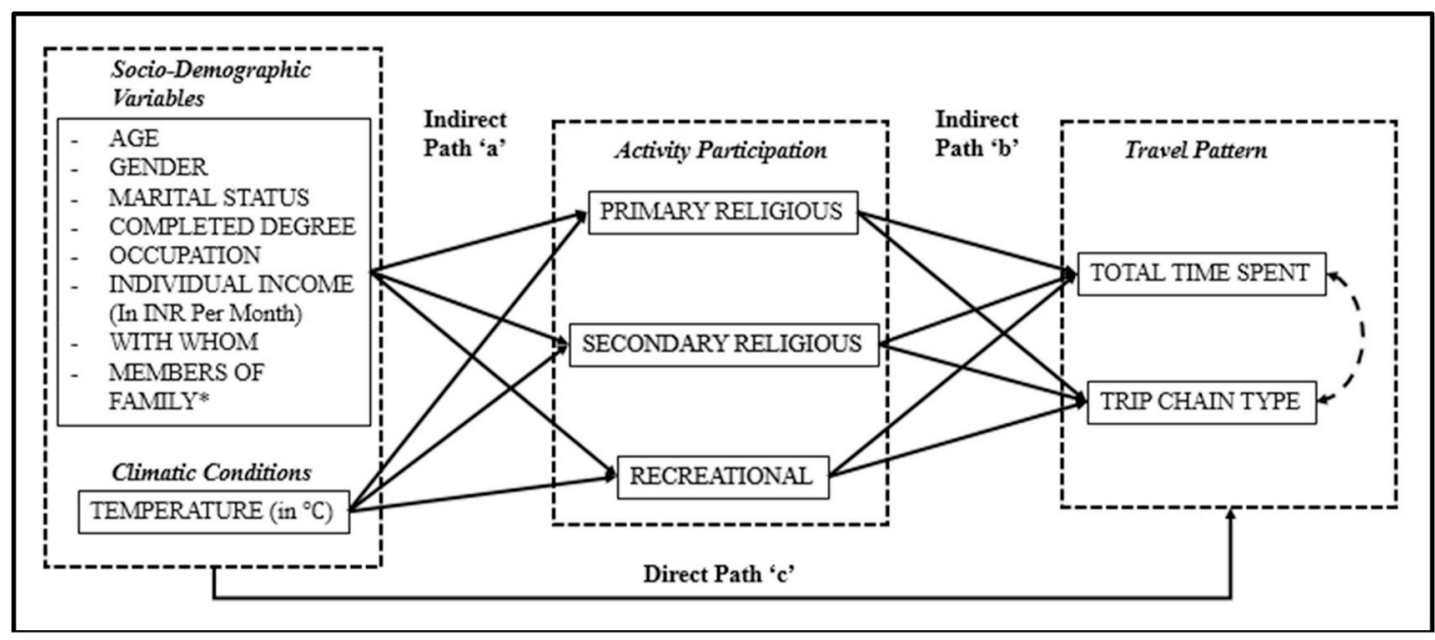

Fig. 1. Overview of SEM framework (Indirect Effect: $=a^{*} b$, Direct Effect: $=c$, Total Effect: $=c+a^{*} b$ ).

Table 1

Activity types and their description.

\begin{tabular}{|c|c|c|}
\hline Primary Activity & Secondary Activity Type & Brief Description \\
\hline $\begin{array}{l}\text { PRIMARY RELIGIOUS } \\
\text { (Prim_Rel) }\end{array}$ & $\begin{array}{l}\text { Offering Prayer/ } \\
\text { Worshipping } \\
\text { Holy Dip } \\
\text { Check-in at Temple } \\
\text { Check out at Temple } \\
\text { Visiting Camp } \\
\text { Listening to Bhajans } \\
\text { Listening to Preaching }\end{array}$ & $\begin{array}{l}\text { To offer prayer or worship idols inside Temple } \\
\text { To take holy bath at one of the Ghats of Kshipra river } \\
\text { Visiting inside premises of the Temple } \\
\text { Visiting outside premises of the Temple } \\
\text { To visit Camp/Akhara and attend spiritual/religious sermons } \\
\text { Listening to Bhajans (religious songs/chanting) at Temple/Akhara } \\
\text { To listen to the preaching of holy men/spiritual gurus at Akhara or from pundits/priests at } \\
\text { Temple }\end{array}$ \\
\hline $\begin{array}{l}\text { SECONDARY RELIGIOUS } \\
\quad(\text { Sec_Rel) }\end{array}$ & $\begin{array}{l}\text { Reading Holy Book } \\
\text { Meeting Naga Sadhu } \\
\text { (Saints) } \\
\text { Making Shiva Lingaa } \\
\text { Serving Food in Temple }\end{array}$ & $\begin{array}{l}\text { To read a holy book near temple premises } \\
\text { To meet Naga Sadhu (Holy men who have given up all worldly pleasures including clothing) } \\
\text { Molding the idol of Lord Shiva from mud } \\
\text { Serving food to pilgrims/devotees at the Temple }\end{array}$ \\
\hline RECREATIONAL (REC) & $\begin{array}{l}\text { Yoga } \\
\text { Shopping } \\
\text { Discussing } \\
\text { Visiting Garden } \\
\text { Taking Photos } \\
\text { Watching TV } \\
\text { Fun Rides } \\
\text { Cleaning Ghats }\end{array}$ & $\begin{array}{l}\text { Performing yoga }{ }^{\mathrm{a}} \\
\text { Shopping from nearby local markets } \\
\text { Discussing and gathering in between pilgrims } \\
\text { Visiting Garden } \\
\text { Taking Selfies/photos } \\
\text { Watching TV at Akhara } \\
\text { Taking fun rides at a circus in Kumbh area } \\
\text { Cleaning Ghats as a voluntary service \& for fun }\end{array}$ \\
\hline DISCRETIONARY (DIS) & $\begin{array}{l}\text { Using Comfort Stations } \\
\text { Sleeping } \\
\text { Keeping Footwear } \\
\text { Changing clothes } \\
\text { Using ATM } \\
\text { Eating Food } \\
\text { Drinking } \\
\text { Waiting for Food } \\
\text { Smoking } \\
\text { Resting }\end{array}$ & $\begin{array}{l}\text { Using toilets } \\
\text { Sleeping at hotel/Akhara } \\
\text { Keeping footwear outside Temple } \\
\text { Changing clothes before/after a holy dip in Kshipra river } \\
\text { Using ATM to withdraw cash } \\
\text { Having snacks/meals } \\
\text { Drinking water/soft drinks or having tea } \\
\text { Waiting for food/Ordering food } \\
\text { Smoking weed/hukkah } \\
\text { Resting at Temple premises in the Kumbh Mela area other than their place of accommodation due } \\
\text { to exhaustion }\end{array}$ \\
\hline
\end{tabular}

${ }^{a}$ Yoga is a Sanskrit word meaning union. It combines physical exercises, mental meditation, and breathing techniques to relieve stress and strengthen muscles. 
This classification more clearly reflected the complexity of individuals' trip chain in a religious setting. The SEM model as specified in the present study is estimated using 'lavaan' package (Rosseel, 2012) in R software (R Core Team, 2020).

\subsection{Ordered logit $(O L)$ specification}

To achieve the second objective of the present paper, individual-level OL models for each activity type were estimated. The main attractions of Kumbh Mela are temples, religious camps (Akhadas), holy saints (Naga sadhus), and Ghats for taking a holy dip in the river. These locations are not concentrated but spatially dispersed throughout the cordoned region of a city where the Kumbh Mela event is carried out. Other temporary arrangements of drinking water, comfort stations are also spread throughout the city. This forces the visitors/pilgrims to make multiple stops in order to participate in various activities. Hence, the number of stops taken by an individual for each activity type (primary religious, secondary religious, recreational, and discretionary) is an ordered outcome and therefore modeled as a dependent variable in the OL regression. As evident from the past studies discussed in subsection 2.2 , explanatory variables such as socio-demographic profile, activity participation, and externalities such as temperature significantly influence an individual's stop-making propensities and hence considered in the present study. The OL models were estimated using the 'Apollo' package (Hess and Palma, 2019) in R software (R Core Team, 2020).

\section{Methodology}

The methodological formulation behind the SEM and OL approaches is presented in detail in the following subsections.

\subsection{Structural equation modeling}

SEM framework is suitable to capture the posited relationship between socio-demographic, activity participation, and travel pattern as hypothesized in the present study. Here as specified in section 3.1, total time spent is a continuous variable while trip chain type and activity participation variables are binary coded. Hence, the observed binary (dichotomous) response can be specified as:

$$
y_{i}=\left\{\begin{array}{ll}
0 & \text { if } y_{i}^{*} \leq \tau \\
1 & \text { if } y_{i}^{*}>\tau
\end{array}\right\}
$$

where $y_{i}^{*}$ is the response propensity, and $\tau$ is the threshold. The response propensity is then expressed in the form of a standard structural equation model without latent factors (Golob, 2003; Kuppam and Pendyala, 2001):

$$
y_{i}^{*}=\alpha+B y_{i}^{*}+\Gamma x_{i}+\varepsilon_{i}
$$

where $y_{i}^{*}$ represents the column vector of $\mathrm{p}$ while $x_{i}$ represents the column vector of $\mathrm{q}$. $\alpha$ represents the threshold values in case of categorical outcomes (for binary and ordinal data) and intercepts for continuous dependent variables, $B$ represents the direct effect coefficients and consists of a matrix of $(p \times p)$ pairs of $\mathrm{p}$ endogenous variables. $\Gamma$ represents the indirect effect coefficients and consists of a matrix of $(p \times q)$ pairs where $q$ is the exogenous variables used in the model. Here, as can be seen from Fig. 1, exogenous variables are those variables from which the paths (symbolized by arrows) will only depart towards endogenous variables pointed by arrowheads. Thus, exogenous variables, either directly or indirectly influence the endogenous variables (Golob, 2003). The error terms are denoted by $\varepsilon_{i}$ whose dimension is $p \times I$, where $I$ denotes an identity matrix of rank $p$. Assuming a probit link function for error term, $\varepsilon_{i}$ is expressed as $\varepsilon_{i}^{\sim} \mathrm{N}\left(0,1-\sigma_{i}^{2}\right)$. Here, $y_{i}^{*}$ is a response propensity (not directly observed) variable and does not have an inherent scale, hence, the variance in the error term $\varepsilon_{i}$ cannot be directly estimated (Muthén, 1984). Consequently, for model identification purposes, parametrization of the error term is considered. Among the two widely used parametrization techniques, the present study considers the 'Delta' method, which is the default parametrization while using 'lavaan' package.

The model parameters are then estimated using a 2-stage procedure. The first step involves the estimation of thresholds and tetrachoric correlation matrix (for binary endogenous variables). In the second stage, the estimated threshold values and tetrachoric correlation matrix obtained from the data are fitted to the hypothesized SEM model used in the present study using various estimation methods (Olsson, 1979). The present study uses the 'Diagonally Weighted Least Square' (DWLS) fit function for estimation. The reason behind using DWLS is that the continuity property of 'Maximum Likelihood' (ML) function does not hold for ordinal and binary endogenous variables (Muthén, 1984). The fit function for DWLS method is given by (Li, 2016; Muthén, 1984; Xia and Yang, 2019):

$$
F_{D W L S}=(s-\sigma(\omega))^{\prime} W_{D W L S}^{-1}(s-\sigma(\omega))
$$

In Eq. iii, $s=\left(s_{1}, s_{2}\right)$, where $s_{1}$ is threshold vector and $s_{2}$ represents the unstructured tetrachoric correlation matrix. $\sigma(\omega)=\left(\sigma_{1}(\omega)\right.$, $\sigma_{2}(\omega)$ ), where $\omega$ is a vector of model parameters (coefficients), $\sigma_{1}(\omega), \sigma_{2}(\omega)$ respectively represent the model implied thresholds and tetrachoric correlation matrix. $W$ is the weight matrix for the DWLS estimation method and is given as $W_{D W L S}=N^{*} \operatorname{diag}(\theta)$ where $N$ is the sample size and $\operatorname{diag}(\theta)$ represents all the diagonal elements of the asymptotic variance-covariance matrix of thresholds and tetrachoric correlations (Li, 2016). For further details regarding the SEM methodology with categorical endogenous variables, the readers are referred to Muthén (1984). 


\subsection{Ordered logit model (OL)}

The econometric details of the standard ordered logit model (McKelvey and Zavoina, 1975) is described as follows. Let the observed dependent variable, i.e., the numbers of stops taken for each activity type is denoted by $y_{i}$, where, $i(i=1,2, \ldots \ldots \ldots, N)$ represents the number of observations. Let $j(j=1,2, \ldots \ldots \ldots, J)$ and $\psi_{j}$ denote the no of stops generated for each activity purpose and the thresholds associated with these stops, respectively. These unknown thresholds partition the propensity to undertake stops into $J-1$ intervals and are in ascending order such that $\psi_{0}<\psi_{1}<\ldots \ldots \ldots \ldots<\psi_{J}$ where $\psi_{0}=-\infty$ and $\psi_{J}=+\infty$.

In traditional ordered logit model, it is assumed that $y_{i}$ is associated with a continuous, latent variable $y_{i}^{*}$ (representing the latent stop making propensities of tourists) and $\psi_{j}$ with a response mechanism of the following form:

$$
y_{i}=j \quad \text { if and only if } \psi_{j-1}<y_{i}^{*}<\psi_{j} \quad j=1,2 \ldots \ldots \ldots, J
$$

The ordered regression equation for $y_{i}^{*}$ is typically a linear function and is given by:

$$
y_{i}^{*}=x_{i}^{\prime} \beta+\varepsilon_{i} \quad \text { for } i=1,2, \ldots \ldots \ldots, N
$$

where, $x_{i}^{\prime}$ is a list of independent variables, $\beta$ is a set of independent vectors to be estimated, $\varepsilon_{i}$ is the random error term and is assumed to be independent and identically distributed (iid) across individuals following a standard logistic distribution.

Based on this assumption of the distribution of error terms, the probability expression of the ordered logit model takes the form as:

$$
\operatorname{Pr}\left(y_{i}=j \mid x, \psi, \beta\right)=F\left(\psi_{j}-x_{i}^{\prime} \beta\right)-F\left(\psi_{j-1}-x_{i}^{\prime} \beta\right)
$$

where $F$ represents the cumulative logistic distribution function, $F=1 /\left(1+\exp \left(-\left(\psi_{j}-x_{i}^{\prime} \beta\right)\right)\right)$. The log-likelihood function is then given by:

$$
L\left(\theta_{1}\right)=\sum_{i=1}^{n} \sum_{j=0}^{k}\left(y_{i}=j\right) \log \left[F_{j}\left(\psi_{j}-x_{i}^{\prime} \beta\right)-F_{j-1}\left(\psi_{j-1}-x_{i}^{\prime} \beta\right)\right]
$$

For further insights on the estimation criteria of maximum likelihood estimate $\widehat{\theta_{1}}$ the readers are referred to Amemiya (1985); Weiss (1997).

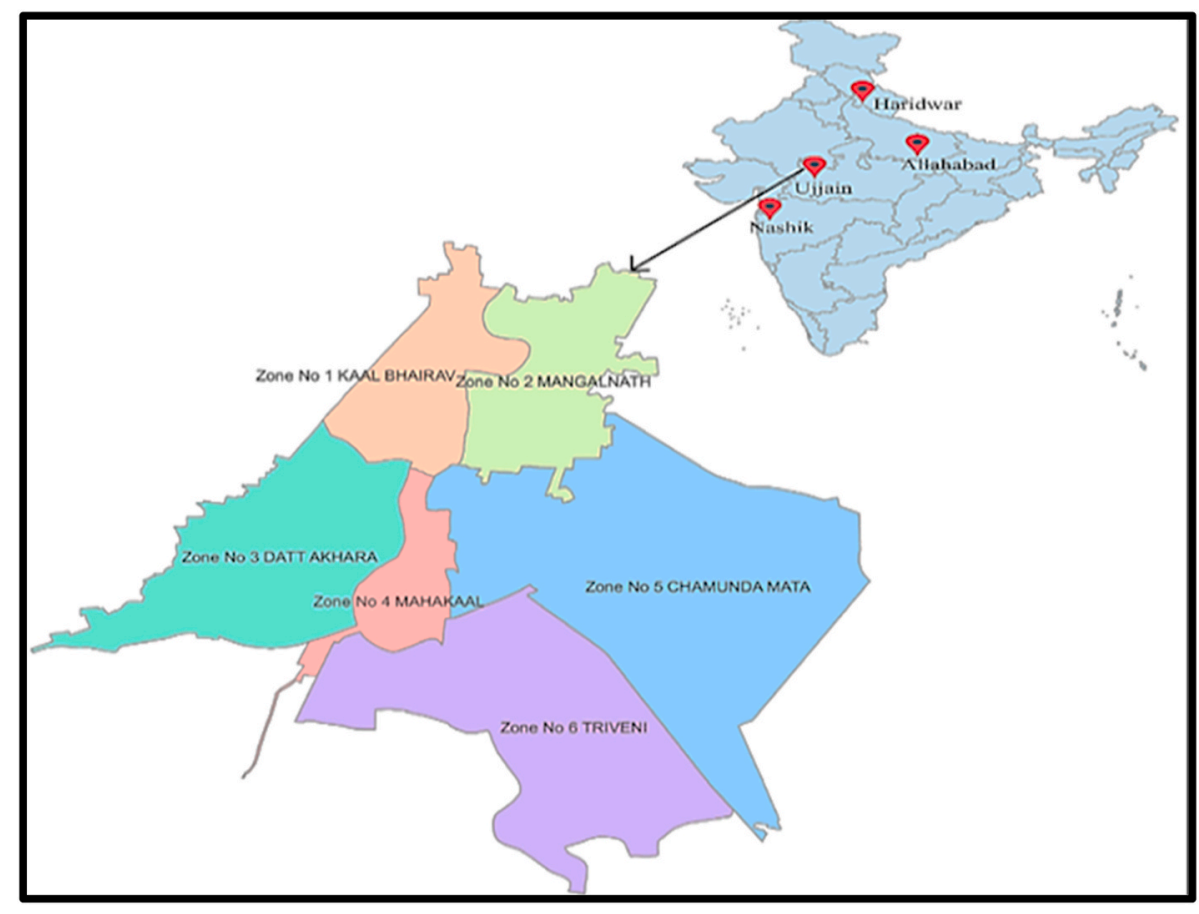

Fig. 2. Geographical representation of Kumbh Mela zones held at Ujjain in 2016. 


\section{Data}

\subsection{Study area \& context}

The present study focuses on the Kumbh Mela event held at Ujjain, India, in 2016 from 22nd April to 21st May. For Kumbh Mela, Ujjain city was divided into six zones, as shown in Fig. 2 and further sub-divided into 22 sectors for better management of the event. Around, 3061 ha of land was acquired for the Kumbh Mela event with 52 ha of land allocated to establish satellite towns. The cordoned off region inside the Ujjain city appeared as a temporary 'pop up city' built on the acquired land with several services like ambulances, hospitals, changing rooms, community kitchens, decorative huts, e-rickshaws, call centers, resting area shelters, toilets, water huts, ATM's, spiritual camps, religious tents etc. available on a temporary basis ("Biggest allocation — Kumbh gets a Central boost: Rs $100 \mathrm{cr}$ to Madhya Pradesh | India News, The Indian Express," n.d.). Together, the central and the state government spent an amount close to $\mathrm{INR}^{4} 4000$ Crore (approx. 530 million USD) for Kumbh Mela ("Biggest allocation — Kumbh gets a Central boost: Rs 100 cr to Madhya Pradesh | India News, The Indian Express," n.d., "Simhastha Kumbh budget may rise to Rs 5,000 crore: MP Govt - The Economic Times, " n.d.) for the establishment of infrastructure in Ujjain city for pilgrims/tourists indicating the massive impact the event has at a global level. Kumbh Mela attracts people from varied demographics (Buzinde et al., 2014) that includes not only visitors from rural and urban India but also from abroad. While, the count of foreigners who had visited Ujjain during Kumbh Mela, 2016 stood at 10,000, there was a footfall of 75 million Indian visitors for this one-month long holy festival according to sources ("Ujjain: As Kumbh draws to a close, devotees throng Kshipra for 'shahi snan' | India News, The Indian Express," n.d.). Moreover, it was estimated that an approximate figure of 12 million people took a holy dip (Shahi Snan) on May 21, 2016, i.e., the concluding day of Kumbh mela.

\subsection{Data collection}

The responses of pilgrims were collected through a questionnaire survey conducted for the entire duration of Kumbh Mela. The questionnaire consisted of two parts. The first part gathered information about the demographic details of pilgrims, and the second part recorded the activity schedule of pilgrims. The medium of instruction for filling out the survey was also available in two languages English and Hindi (local language). However, as the composition of the tourists/visitors visiting Kumbh Mela is unknown due to the several constraints associated with the nature of the event, they were chosen randomly from various hotels, bus stops, Dharamshala, and Akharas. These locations were randomly scattered across the Ujjain city. Besides, such spots were either the resting or starting points of an individual's tour and hence served as survey hotspots. The face-to-face survey process was carried out by volunteers who would approach an individual, explain to them the purpose of the survey, and invite them to participate in it. If individuals give their consent, then the volunteer would collect the demographic details of the individual. For the second part of the questionnaire, volunteers gathered information on individual's activity participation timing, location, and whether the activity was performed alone or jointly. This task was performed by accompanying the pilgrims in their journey with wearable GPS devices. All the volunteers were given extensive training, including mock drills, to record the travel data in real-time.

\subsection{Sample formation \& description}

\subsubsection{Exogenous variables}

A total of 3844 survey responses were collected. After excluding the biased samples and filtering out the incomplete questionnaires as well as activity diaries with only discretionary activity participation, the present study considers 2523 sample points. Table 1 enlists the socio-demographic variables as well as other exogenous variables used in the present study. In the sample, individuals of age group $18-25$ years hold a majority share of $31.224 \%$, while only $5.717 \%$ of visitors/tourists are in the age group of 65 years and above. In the gender category, about $60 \%$ of pilgrims were males and $40 \%$ females. About $65 \%$ of pilgrims reported themselves as married and $35 \%$ as unmarried. In case of highest completed degree, nearly one-third of the visitors had completed up to high school (tenth), approx. $22 \%$ up to intermediate (twelfth), and more than $45 \%$ had completed graduation or higher. The occupation category had five levels student, home-makers, government employees, private employees, and self-employed. Here, self-employed refers to individuals who are retired, farmers, business people, etc. by occupation whose share is close to $23 \%$. As can be seen from Table 1 , the share of students and home-makers are nearly equal, with individual shares slightly above than one-fourth share of the total sample. Further, majority of pilgrims (slightly above 63\%) earned less than INR 10,000 per month, followed by INR 10,000-20,000 per month category (14\%) and then INR 20,000-30,000 per month (11\%). The sample summary also reports that most of the individuals have come along with their families (67\%) to attend Kumbh. As Kumbh Mela is a religious event, the general observation is that the pilgrims would visit such mass gatherings along with their family.

The continuous exogenous variables include -members of a family (including relatives) visiting Kumbh, and daily temperature averaged over the entire duration (April 22, 2016 to May 21, 2016) of Kumbh. Unlike the categorical individual attributes whose sample share is expressed in percentage, these continuous variables are summarized through mean and standard deviation. From Table 1, it is observed that mean family troupe visiting Kumbh is close to 6 members which is in accordance to the past studies on crowd dynamics that have found that social groups with an average group size of six persons are quite frequent at public events

\footnotetext{
${ }^{4}$ INR $=$ Indian Rupee.
} 
Table 2

List of Exogeneous (Independent) variables and their share in percentages (Sample Size, $N=2523$ ).

\begin{tabular}{|c|c|c|c|c|c|}
\hline Categories & Variables & Share in $\%$ & Categories & Variables & Share in \% \\
\hline \multirow[t]{6}{*}{ AGE (In Years) } & $18-25$ & 31.224 & OCCUPATION & Student (Stu) & 27.665 \\
\hline & $25-35$ & 18.787 & & Home-Makers (HM) & 25.922 \\
\hline & $35-45$ & 20.016 & & Government (Govt) & 10.266 \\
\hline & $45-55$ & 14.586 & & Private (Pvt) & 13.397 \\
\hline & $55-65$ & 9.671 & & Self-Employed ${ }^{\mathrm{a}}$ & 22.751 \\
\hline & $\geq 65^{\mathrm{a}}$ & 5.717 & $\begin{array}{l}\text { INDIVIDUAL INCOME (In INR Per } \\
\text { Month) }\end{array}$ & $\begin{array}{l}\text { Less than } 10,000 \text { (LT } \\
10 \mathrm{~K} \text { ) }\end{array}$ & 63.377 \\
\hline \multirow[t]{2}{*}{ GENDER } & Male & 59.849 & & $\begin{array}{l}10,000-20,000 \\
(10 \mathrm{~K}-20 \mathrm{~K})\end{array}$ & 14.348 \\
\hline & Female $^{\mathrm{a}}$ & 40.151 & & $\begin{array}{l}20,000-30,000 \\
(20 \mathrm{~K}-30 \mathrm{~K})\end{array}$ & 11.494 \\
\hline MARITAL STATUS & Married & 64.725 & & 30,000 or Above $\mathrm{a}^{\mathrm{a}}$ & 10.781 \\
\hline (MAR_STAT) & Unmarried $^{\mathrm{a}}$ & 35.275 & WITH WHOM & Alone & 6.619 \\
\hline \multirow[t]{5}{*}{ COMPLETED DEGREE } & Primary (Prim) & 20.571 & & Family & 67.054 \\
\hline & $\begin{array}{l}\text { High School } \\
\text { (Hi_Sch) }\end{array}$ & 12.089 & & Friends & 20.809 \\
\hline & Intermediate (Inter) & 21.799 & & Tour Group ${ }^{a}$ & 5.518 \\
\hline & Graduate (Grad) & 33.611 & MEMBERS OF FAMILY (MEM_FAM) $)^{b}$ & & $5.572 \pm 2.334$ \\
\hline & Post-Graduate $^{\mathrm{a}}$ & 11.930 & DAILY TEMPERATURE $\left(\right.$ in $\left.{ }^{\circ} \mathrm{C}\right)(T E M P)^{b}$ & & $\begin{array}{l}32.552 \pm \\
2.458\end{array}$ \\
\hline
\end{tabular}

${ }^{\text {a }}$ Indicates those variables were taken as a reference during the analysis.

${ }^{\mathrm{b}}$ Represents mean \pm standard deviation for the continuous variable. Rest all are expressed in $\%$.

Table 3

List of Endogenous (Dependent) variables and their descriptive summary $(\mathrm{N}=2523)$.

\begin{tabular}{|c|c|c|c|}
\hline Categories & & Variables & Share in $\%$ \\
\hline TOTAL TIME SPENT ${ }^{b}$ (in minutes) (TTS) & & & $102.943 \pm 101.606$ \\
\hline \multirow[t]{2}{*}{ TRIP CHAIN TYPE (TC_Type) } & \multirow[b]{3}{*}{ Participation in \% } & Simple $^{\mathrm{a}}$ & 8.759 \\
\hline & & Complex & 91.241 \\
\hline Activity Type & & Episode Frequency & Count in \% \\
\hline \multirow[t]{7}{*}{ PRIMARY RELIGIOUS (Prim_Rel) } & \multirow[t]{7}{*}{93.262} & 0 & 6.738 \\
\hline & & 1 & 18.113 \\
\hline & & 2 & 20.531 \\
\hline & & 3 & 17.004 \\
\hline & & 4 & 16.013 \\
\hline & & 5 & 11.464 \\
\hline & & $\geq 6$ & 10.138 \\
\hline \multirow[t]{3}{*}{ SECONDARY RELIGIOUS (Sec_Rel) } & \multirow[t]{3}{*}{22.117} & 0 & 77.883 \\
\hline & & 1 & 12.830 \\
\hline & & $\geq 2$ & 9.287 \\
\hline \multirow[t]{4}{*}{ RECREATIONAL (REC) } & \multirow[t]{4}{*}{44.312} & 0 & 55.688 \\
\hline & & 1 & 27.269 \\
\hline & & 2 & 9.592 \\
\hline & & $\geq 3$ & 7.451 \\
\hline \multirow[t]{7}{*}{ DISCRETIONARY (DIS) } & \multirow[t]{7}{*}{83.789} & 0 & 16.211 \\
\hline & & 1 & 21.760 \\
\hline & & 2 & 13.635 \\
\hline & & 3 & 14.507 \\
\hline & & 4 & 8.244 \\
\hline & & 5 & 16.013 \\
\hline & & $\geq 6$ & 9.631 \\
\hline
\end{tabular}

a Indicates those variables were taken as reference during the analysis.

b Represents mean \pm standard deviation for the continuous variable.

(Oberhagemann et al., 2014) while the average daily temperature is close to $33^{\circ} \mathrm{C}$.

\subsubsection{Endogenous variables}

Table 3 below presents the list endogenous (dependent) variables and their descriptive summary. For the SEM model, the individual activity participation rate (expressed in \%), as well as the total time spent and trip chain type of an individual, are endogenous 
variables. From the table, it is found that participation in primary religious activity had a massive share of $93.26 \%$, indicating that majority of visitors to Kumbh are most likely to participate in activities that are clubbed under the 'Primary Religious' category. The participation rate in secondary religious and recreational activities are $22 \%$ and $44 \%$, respectively. These participation shares reflect that secondary religious and recreational activities are also an essential part of an individual's religious pilgrimage. Next, as discussed in section 3.1, the total time spent variable is the aggregate time spent by an individual at Kumbh Mela in performing primary religious, secondary religious and recreational activities (time spent in discretionary activities is not considered in SEM model). It is expressed in terms of mean (and standard deviation). As observed from the table, an individual approximately spends 103 min in during his/her visit to Kumbh. The trip chain variable is binary coded with simple and complex chains having share $9 \%$ and $91 \%$, respectively. The higher share of complex chains is mainly due to fact that in a mass religious event like Kumbh Mela, pilgrims participate in multiple combinations of mandatory and non-mandatory activities to fulfill their religious belief and faith (Raj et al., 2015).

Furthermore, from the OL model perspective, Table 3 presents the number of activity episodes and their share in percentage for each activity type. Among those who participated in primary religious activity, the number of episodes undertook by them has been divided into seven categories. It can be seen that as the episode categories (frequency) increases the propensity of undertaking that many episodes gradually decrease. This indicates the spatial and temporal constraints that a pilgrim faces while taking multiple episodes. A similar trend is observed across secondary religious and recreational activities, which have three- and four-episode categories, respectively. However, for discretionary activities, no clear pattern is observed. Moreover, as the activity spaces are distributed over the entire Kumbh cordoned off region, resting in between these spaces becomes a necessity due to exhaustion and fatigue as crowd movement is mainly by walking. These resting stops have contributed to a higher number of stops under discretionary activities.

\section{Empirical analysis}

This section provides the estimation results of the SEM and OL models that are proposed in this study. Overall model fit parameters, significant coefficients of each of these models as well the behavioral interpretation of the findings are discussed in brief in the following sections.

\subsection{SEM estimation results}

\subsubsection{Model fit measures}

The fit statistic of the final SEM model, as well as the model parameters, are reported in Table 4. As the DWLS estimator is used to minimize the fit function, it yields a robust mean- and variance-adjusted chi-square value (Li, 2016; Muthén, 1984), which measures the difference between the observed and final estimated model covariance. The model has a $\chi^{2}$ value of 161.259 with 46 degrees of freedom (df) resulting in a ratio of $\left[\frac{\chi^{2}}{d f}\right]$ as 3.506, which implies a reasonable fit (Xia and Yang, 2019), however, as reported in SEM literature $\chi^{2}$ is sample biased. Therefore, Table 4 also reports various other model fit indices that determine the best fit model. As can be seen, all the reported fit indices except the WRMR value are within the acceptable cut-off values (Xia and Yang, 2019). These fit indices, thus, provide tenable evidence regarding the acceptability of the final structured model as compared to the original baseline model and hence leads to the rejection of the null hypothesis, implying there is no significant difference in baseline and final model.

Table 4 also presents other model parameters, i.e., thresholds (or intercepts) and robust R square value of the endogenous variables. The threshold (or intercepts) values for all the endogenous variables were found to be significant at $90 \%$ CI. However, they do not have any behavioral interpretations. Next, the robust r-square reported in the table represents the McKelvey and Zavoina Pseudo R-square, as documented by the 'lavaan' package (Rosseel, 2012). Among all endogenous variables, the model best explains the variance (highest $\mathrm{R}$ square value) in primary religious activity participation while it least explains the discrepancy in participation for secondary religious

Table 4

Fit Statistics and model parameters of SEM model $(\mathrm{N}=2523)$.

\begin{tabular}{|c|c|c|}
\hline Model Fit Measures & Cut-off value & Model Based Value \\
\hline$\chi^{2}=$ Robust Chi-square; $\mathrm{df}=$ degrees of freedom & $p<0.05$ & $\begin{array}{l}161.259(46) \\
p=0.000\end{array}$ \\
\hline RMSEA = Root Mean Square Error of Approximation & $<0.08$ & 0.032 \\
\hline$W R M R=$ Weighted Root Mean Square Residual & $<1$ & 1.142 \\
\hline$C F I=$ Comparative Fit Index & $>0.90$ & 0.953 \\
\hline$T L I=$ Tucker Lewis Index & $>0.90$ & 0.987 \\
\hline$G F I=$ Goodness of Fit Index & $>0.90$ & 0.973 \\
\hline Endogenous Variables & Thresholds/Intercepts (t-stats) & Robust R Square \\
\hline PRIMARY RELIGIOUS & $-5.136(-10.843)$ & 0.515 \\
\hline SECONDARY RELIGIOUS & $0.975(2.254)$ & 0.163 \\
\hline RECREATIONAL & $-1.381(-3.471)$ & 0.247 \\
\hline TRIP CHAIN TYPE & $0.668(1.905)$ & 0.269 \\
\hline TOTAL TIME SPENT & $3.983(8.574)$ & 0.439 \\
\hline
\end{tabular}


Table 5

Estimation results of the final SEM model $(\mathrm{N}=2523)$.

\begin{tabular}{|c|c|c|c|c|c|c|c|c|c|c|c|}
\hline \multirow[t]{2}{*}{ Endogenous Variables $\downarrow$} & \multicolumn{5}{|c|}{ AGE (In Years) } & \multirow{2}{*}{$\frac{G E N D E R}{\text { Male }}$} & \multirow{2}{*}{$\frac{M A R \_S T A T}{\text { Married }}$} & \multicolumn{4}{|c|}{ COMPLETED DEGREE } \\
\hline & $18 \_25$ & 25_35 & $35 \_45$ & 45_55 & $55 \_65$ & & & Prim & Hi_Sch & Inter & Grad \\
\hline \multirow[t]{3}{*}{ Prim_Rel } & $-{ }^{a}$ & - & - & - & - & -0.061 & 0.177 & 0.409 & 0.411 & 0.509 & 0.325 \\
\hline & $-b$ & - & - & - & - & -0.061 & 0.177 & 0.409 & 0.411 & 0.509 & 0.325 \\
\hline & $-c$ & - & - & - & - & - & - & - & - & - & - \\
\hline \multirow[t]{3}{*}{ Sec_Rel } & -0.414 & -0.419 & -0.383 & -0.333 & - & 0.004 & -0.174 & - & -0.156 & -0.239 & -0.297 \\
\hline & -0.414 & -0.419 & -0.383 & -0.333 & - & 0.004 & -0.174 & - & -0.156 & -0.239 & -0.297 \\
\hline & - & - & - & - & - & - & - & - & - & - & - \\
\hline \multirow[t]{3}{*}{ REC } & -0.328 & -0.117 & -0.279 & -0.284 & -0.291 & - & 0.126 & - & - & - & - \\
\hline & -0.328 & -0.117 & -0.279 & -0.284 & -0.291 & - & 0.126 & - & - & - & - \\
\hline & - & - & - & - & - & - & - & - & - & - & - \\
\hline \multirow[t]{3}{*}{ TTS } & -0.563 & -0.527 & -0.448 & -0.313 & -0.066 & -0.150 & 0.012 & 0.242 & 0.180 & 0.205 & 0.072 \\
\hline & -0.455 & -0.378 & -0.343 & -0.230 & -0.119 & -0.116 & - & - & - & - & - \\
\hline & -0.108 & -0.149 & -0.105 & -0.083 & 0.053 & -0.034 & 0.012 & 0.242 & 0.180 & 0.205 & 0.072 \\
\hline \multirow[t]{3}{*}{ TC_Type } & -0.256 & -0.147 & 0.325 & 0.076 & -0.487 & -0.002 & 0.008 & -0.589 & -0.182 & -0.408 & -0.512 \\
\hline & -0.358 & -0.311 & 0.224 & - & -0.404 & -0.038 & - & -0.335 & - & -0.204 & -0.450 \\
\hline & 0.102 & 0.164 & 0.101 & 0.076 & -0.083 & 0.036 & 0.008 & -0.254 & -0.182 & -0.204 & -0.062 \\
\hline \multirow[t]{2}{*}{ Endogenous Variables $\downarrow$} & \multicolumn{4}{|c|}{ OCCUPATION } & \multicolumn{3}{|c|}{ INDIVIDUAL INCOME } & \multicolumn{3}{|c|}{ WITH WHOM } & MEM_FAM \\
\hline & Stu & $\mathrm{HM}$ & Govt & Pvt & LT $10 \mathrm{~K}$ & $10 \mathrm{~K}-20 \mathrm{~K}$ & $20 \mathrm{~K}-30 \mathrm{~K}$ & Alone & Family & Friends & \\
\hline \multirow[t]{3}{*}{ Prim_Rel } & $\overline{-a}$ & 0.053 & -0.213 & - & -0.195 & - & 0.351 & -4.140 & 3.823 & -3.910 & 0.221 \\
\hline & $-\mathbf{b}$ & 0.053 & -0.213 & - & -0.195 & - & 0.351 & -4.140 & 3.823 & -3.910 & 0.221 \\
\hline & $-c$ & - & - & - & - & - & - & - & - & - & - \\
\hline \multirow[t]{3}{*}{ Sec_Rel } & - & - & - & - & - & - & - & - & - & 0.411 & - \\
\hline & - & - & - & - & - & - & - & - & - & 0.411 & - \\
\hline & - & - & - & - & - & - & - & - & - & - & - \\
\hline \multirow[t]{3}{*}{ REC } & - & 0.222 & - & -0.395 & -0.105 & -0.169 & 0.174 & 0.566 & 0.284 & - & 0.432 \\
\hline & - & 0.222 & - & -0.395 & -0.105 & -0.169 & 0.174 & 0.566 & 0.284 & - & 0.432 \\
\hline & - & - & - & - & - & - & - & - & - & - & - \\
\hline \multirow[t]{3}{*}{ TTS } & - & 0.146 & -0.126 & -0.071 & -0.396 & -0.203 & 0.176 & -0.640 & 3.735 & 4.049 & 0.010 \\
\hline & - & 0.155 & - & - & -0.300 & -0.234 & - & 1.913 & 1.523 & 1.568 & -0.043 \\
\hline & - & -0.009 & -0.126 & -0.071 & -0.096 & 0.031 & 0.176 & -2.553 & 2.212 & 2.481 & 0.053 \\
\hline TC_Type & 0.205 & 0.031 & 0.253 & -0.365 & -0.091 & 0.268 & 0.169 & 0.360 & -5.009 & -5.184 & -0.015 \\
\hline & 0.205 & - & 0.121 & -0.253 & - & 0.316 & - & -2.376 & -2.712 & -2.558 & - \\
\hline & - & 0.031 & 0.132 & -0.112 & -0.091 & -0.048 & 0.169 & 2.736 & -2.297 & -2.626 & -0.015 \\
\hline Endogenous Variables $\downarrow$ & Temp & & Prim_Rel & & Sec_Rel & & REC & & & & \\
\hline Prim_Rel & $-\mathbf{a}$ & & - & & - & & - & & & & \\
\hline & -b & & - & & - & & - & & & & \\
\hline & $-c$ & & - & & - & & - & & & & \\
\hline Sec_Rel & 0.026 & & - & & - & & - & & & & \\
\hline & 0.026 & & - & & - & & - & & & & \\
\hline & - & & - & & - & & - & & & & \\
\hline REC & -0.040 & & - & & - & & - & & & & \\
\hline & -0.040 & & - & & - & & - & & & & \\
\hline & - & & - & & - & & - & & & & \\
\hline TTS & -0.031 & & 0.592 & & 0.405 & & 0.181 & & & & \\
\hline & -0.049 & & 0.592 & & 0.405 & & 0.181 & & & & \\
\hline & 0.018 & & - & & - & & - & & & & \\
\hline TC_Type & -0.001 & & -0.622 & & -0.471 & & 0.284 & & & & \\
\hline & - & & -0.622 & & -0.471 & & 0.284 & & & & \\
\hline & -0.001 & & - & & - & & - & & & & \\
\hline
\end{tabular}

a, b, c here represents the total, direct and indirect effects respectively. All the coefficients are significant at $10 \%$ level. 
activities. The model also reports a significant negative covariance of 0.114 between total time spent and trip chain type.

\subsubsection{Interpretation of SEM model results}

The causal effect (direct, indirect, and total effect) of exogenous variables (listed in Table 2) on the endogenous variables (listed in Table 3) is reported in Table 5. Only those variables whose coefficient is found to be significant at $90 \%$ confidence interval (CI) are reported.

As observed from Table 5, irrespective of the individual subgroups, age variable has no significant effect on the decision of an individual to participate in primary religious (Prim_Rel) activity while it has a negative association (both direct and total effect) with secondary religious (Sec_Rel) and recreational (REC) activity participation decision of individuals at Kumbh Mela. A similar pattern is also observed for the direct, indirect, and total effect of all age groups on the total time spent (TTS). This observation may be the outcome of the previous finding, i.e., with an increase in age groups, the activity participation rate decreases (secondary religious and recreational activities) and hence the total time spent in these activities. However, age group has a mixed effect on the trip chain type (TC_Type). The results indicate that young (below the age of 35) and old (above 55 years) age visitors prefer participating in single activities (hence simple chains) while middle-aged individuals participate in multiple combinations of activities, and thus their trip pattern is complex. Male tourists have a positive participation rate in secondary religious activities, while the effects are negative for primary religious activities. Such an observation may be a reflection of the general behavior of families visiting Kumbh Mela, where it is observed that male members mostly engage themselves in reading holy books, meeting holy men and serving food to devotees etc. while female members participate in offering prayers to deities, worshipping idols inside temple premises etc. Besides, as indicated by the model, male members are less likely to undertake multiple episodes (complex trip chains) in a religious context. This particular finding in a religious context is in stark contrast to the studies on out-of-home activity participation (Chen and Akar, 2017; Yang et al., 2010) where males are more prone to take complex trip chains than females. Married individuals may pursue more primary religious and recreational activities and spend less amount of time in secondary religious activities. In addition, the positive (indirect)

Table 6

Estimation Results for OL model for the episodes undertaken for four major activity types $(\mathrm{N}=2523)$.

\begin{tabular}{|c|c|c|c|c|c|c|c|c|c|}
\hline \multirow[t]{2}{*}{ Categories } & \multirow[t]{2}{*}{ Variables } & \multicolumn{2}{|c|}{ Primary religious } & \multicolumn{2}{|c|}{ Secondary religious } & \multicolumn{2}{|l|}{ Recreational } & \multicolumn{2}{|c|}{ Discretionary } \\
\hline & & Coefficient & T-Stat & Coefficient & T-Stat & Coefficient & T-Stat & Coefficient & t-Stat \\
\hline \multirow[t]{5}{*}{ AGE (In Years) } & $18-25$ & - & - & 0.706 & 3.373 & - & - & 0.725 & 3.714 \\
\hline & $25-35$ & - & - & 0.665 & 3.839 & 0.134 & 1.686 & 0.726 & 3.967 \\
\hline & $35-45$ & 0.134 & 2.369 & 0.682 & 4.034 & 0.322 & 1.748 & - & - \\
\hline & $45-55$ & -0.292 & -2.654 & - & - & -0.271 & -2.345 & -0.786 & -4.035 \\
\hline & $55-65$ & - & - & - & - & -0.142 & -1.657 & -0.605 & -2.978 \\
\hline GENDER & Male & -0.069 & -1.878 & - & - & - & - & 0.097 & 2.225 \\
\hline MAR_STAT & Married & 0.131 & 1.735 & -0.252 & -2.475 & - & - & - & - \\
\hline \multirow[t]{4}{*}{ COMPLETED DEGREE } & Prim & - & - & -0.574 & -3.976 & 0.316 & 2.819 & 0.380 & 3.684 \\
\hline & HS & 0.201 & 1.807 & - & - & - & - & - & - \\
\hline & Inter & 0.158 & 1.817 & - & - & -0.238 & -2.343 & - & - \\
\hline & Grad & - & - & 0.255 & 2.301 & - & - & -0.335 & -4.157 \\
\hline \multirow[t]{4}{*}{ OCCUPATION } & Student & - & - & - & - & 0.702 & 3.691 & - & - \\
\hline & $\mathrm{HM}$ & 0.343 & 1.988 & - & - & -0.304 & -2.523 & - & - \\
\hline & Govt & -0.199 & -2.566 & - & - & - & - & - & - \\
\hline & Pvt & - & - & -0.243 & -1.998 & - & - & - & - \\
\hline \multirow[t]{3}{*}{ INDIVIDUAL INCOME (In INR per month) } & LT $10 \mathrm{~K}$ & - & - & - & - & 0.239 & 1.747 & 0.308 & 3.102 \\
\hline & $10 \mathrm{~K}-20 \mathrm{~K}$ & - & - & - & - & 0.376 & 2.390 & 0.647 & 3.518 \\
\hline & $20 \mathrm{~K}-30 \mathrm{~K}$ & - & - & - & - & 0.366 & 2.247 & 0.205 & 1.755 \\
\hline \multirow[t]{3}{*}{ WITH WHOM } & Alone & - & - & - & - & -0.910 & -5.323 & - & - \\
\hline & Family & 0.094 & 2.051 & 0.342 & 3.440 & - & - & -0.831 & -4.637 \\
\hline & Friends & -0.178 & -2.118 & - & - & 0.405 & 3.295 & 0.953 & 4.850 \\
\hline MEMBERS OF FAMILY & & 0.038 & 2.490 & - & - & -0.854 & -3.792 & 0.122 & 2.406 \\
\hline $\operatorname{TEMP}\left(\right.$ in $\left.{ }^{\circ} \mathrm{C}\right)$ & & - & - & - & - & -0.104 & -6.315 & -0.044 & -3.021 \\
\hline \multirow[t]{4}{*}{ ACTIVITY PARTICIPATION } & Prim_Rel & - & - & 1.642 & 8.245 & - & - & -1.176 & -7.163 \\
\hline & Sec_Rel & 0.361 & 4.004 & - & - & -0.187 & -1.867 & 0.621 & 6.682 \\
\hline & REC & 0.138 & 1.920 & -0.494 & -4.822 & - & - & - & - \\
\hline & DIS & 1.567 & 4.416 & - & - & 0.387 & 3.517 & - & - \\
\hline \multirow[t]{6}{*}{ THRESHOLD PARAMETERS } & $0 \mid 1$ & -2.683 & -5.422 & -1.274 & -4.926 & -3.190 & -5.703 & -0.250 & -1.831 \\
\hline & $1 \mid 2$ & -1.015 & -2.063 & -0.513 & -1.990 & -1.787 & -3.205 & -0.957 & -3.166 \\
\hline & $2 \mid 3$ & 0.044 & 2.010 & & & 0.825 & -2.478 & 1.533 & 5.060 \\
\hline & $3 \mid 4$ & 0.737 & 1.752 & & & & & 2.157 & 7.114 \\
\hline & $4 \mid 5$ & 1.546 & 3.135 & & & & & 2.574 & 8.484 \\
\hline & $5 \mid 6$ & 2.344 & 4.741 & & & & & 3.799 & 12.373 \\
\hline \multicolumn{10}{|l|}{ MODEL PARAMETERS } \\
\hline Final Log-Likelihood & & -4645.845 & & -1626.175 & & -2713.302 & & -4709.767 & \\
\hline Initial Log-Likelihood & & -5356.079 & & -3179.111 & & -3454.554 & & -5828.765 & \\
\hline Estimated Parameters & & 20 & & 12 & & 20 & & 22 & \\
\hline AIC Values & & 9331.690 & & 3276.350 & & 5466.604 & & 9463.534 & \\
\hline
\end{tabular}


association between marital status (MAR_STAT) and trip chain type (TC_Type) indicates that married individuals visiting Kumbh mostly come with their families; hence, they show a tendency to participate in multiple primary religious and secondary activities, thus, adding to the complex nature of trip chaining. The effect of completed educational level (COMPLETED DEGREE) of individuals on activity participation and travel pattern is studied by including dummy variables for primary (Prim), high-school (Hi_Sch), intermediate (Inter), and graduate (Grad) levels with post-graduate serving as the reference category. It is observed that all educational levels are positively varying with the individual's participation frequency in primary religious (Prim_Rel) activities as well as his/her total time spent at Kumbh Mela. However, the effects (both direct and indirect) are reversed for secondary religious (Sec_Rel) and trip chain type (TC_Type). From such contrasting findings, one can conclude that with all else being equal, irrespective of the completed educational level of an individual, he/she has a higher propensity to engage in primary religious activities and allocate more time in performing those activities and hence has a simple trip chain pattern.

The nature of association between the occupation of an individual, activity participation, and travel pattern is measured mainly through the four occupation categories, namely - Student (Stu), Home-Makers (HM), Government (Govt), and Private (Pvt) with selfemployed as the base category. Student category has no significant effect on the activity participation and travel pattern except for positive isolated effects on the trip chain type. Next, for home-makers, the results suggest that they have a higher participation rate in primary religious and recreational activities. On the other hand, individuals who are employed in the government or private sector are observed to have a lower participation rate in primary religious and recreational activities, respectively. The effect of occupational categories is, however, more pronounced for trip chain type than for total time spent. Except for private employees, all other groups have a higher propensity to undertake complex trip chains. Similar to the Occupation variable, individual income levels have no significant effect on the decision to participate in secondary religious activities. Judging from the total effects, individuals with monthly income bracket of ' $20 \mathrm{~K}-30 \mathrm{~K}$ ' tend to increase their participation in primary religious and recreational activities while a reverse pattern is observed for individuals whose monthly income lies in the range of 'LT 10K'. Similar behavior is also observed for these two income groups for total time spent as well as trip chain type. Furthermore, visitors to Kumbh accompanied by their families or friends have a higher tendency to spend time on various activities than those visitors who travel to Kumbh all alone which is as per the general perception that people who are in groups in such crowd gatherings feel a sense of togetherness and comfortable in allocating time for various activities. However, the total effects on trip chain type reveal that individuals who come in groups (either with families or friends) tend to decrease their propensity of taking complex trip chains due to the safety perception in such crowded gatherings (Gayathri et al., 2017). The effect of members of family (Mem_Fam) visiting Kumbh Mela, can be related to that of 'With Family' variable for 'WITH WHOM' category. As for the association between daily temperature (TEMP), and endogenous variables, it is found that temperature is negatively associated with that of recreational activity participation, total time spent, and trip chain type. This suggests that with an increase in daily temperature, visitors restrain themselves from taking multiple episodes and spending more time at Kumbh Mela. However, temperature is positively associated with that of secondary religious activity participation. Such association may be explained from the fact that secondary religious activities were mostly performed inside temple premises where sheds were available.

With respect to relationships from activity participation to the total time spent, a clear trade-off is seen in the time spent behavior of individuals subjected to their participation in primary religious, secondary religious, and recreational activities. That is to say, individuals who participate in primary and secondary religious activities tend to spend more time at Kumbh as compared to individuals who primarily visit for recreational purposes. Because of spending a considerable amount of time in primary and secondary religious activities, these individuals are less likely to undertake complex chains or multiple episodes, which is reflected by the negative association between activity participation (except recreational activity) and trip chain type. Moreover, the total time spent at Kumbh is negatively related to trip chain type (as indicated by the covariance value of -0.114 ). In other words, as time spent in various activities increases, the propensity of taking multiple trips at Kumbh Mela relatively decreases, which is quite an interesting observation.

\subsection{OL estimation results}

\subsubsection{Interpretation of ordered logit model results}

The fit indices that include the initial and final log-likelihood (LL) values and Akaike's Information Criterion (AIC) values at convergence, as well as the coefficients of exogenous variables for the four individual ordered logit models are reported in Table 6. The threshold values represent the demarcation points for the observed ordered discrete number of stops for each activity type and are found to be significant for each of the individual OL models at $90 \%$ confidence interval (CI). However, they do not have any behavioral interpretations. In addition, all exogenous variables whose estimates are found to be statistically significant at $90 \%$ confidence interval $\left(\mathrm{t}_{0.90}=1.645\right)$ are reported in Table 6 and are discussed in the following paragraphs.

The results in Table 6 indicate that various socio-demographic variables significantly influence the stop making propensity of tourists visiting Kumbh Mela. As for age variable, the results indicate that individuals in the age group of 18-45 are more likely to undertake a higher number of stops for participating in various activities as compared to individuals who are above the age of 45 years. Such an observation may stem from the fact that young and/or middle-aged individuals (in the age range of 18-45) are more physically active than older individuals (above 45 years) and hence such physical constraints restrain older individuals from taking multiple stops in mas crowd gathering events such as Kumbh Mela. In case of gender, males have a lower tendency to take multiple stops for primary religious activities while they have a positive association with the number of discretionary activity stops being taken. This is consistent with the expectation that in a religious setting, females are more likely to take multiple stops to participate in various primary religious activities because of their greater religious affinity. Married individuals (MAR_STAT) who are mostly accompanied by their family members have a higher probability of taking multiple stops to engage themselves in various primary religious activities while the same 
cannot be said for secondary religious activities. The estimation results for various sub-categories of the highest complete degree (educational level) is then studied. The results indicate that visitors to Kumbh who had primary (Prim) level of education are more inclined to indulge in recreational and discretionary activities. On the other hand, individuals who have completed intermediate (Inter) or are graduates (Grad) are more likely to get involved in primary religious and secondary religious activities, respectively. Present occupation status seems to have a moderate effect on the stop-making propensity of individuals visiting Kumbh Mela. As expected, home-makers (HM) are more inclined to undertake primary religious episodes while students have a higher inclination towards recreational activities. This is in accordance with the general perception that the former comes to gain spiritual and religious knowledge while the latter is more concerned with exploring places and enjoying their stay at Ujjain Kumbh Mela. Individuals who are either employed in the public sector (Govt) or private (Pvt) sector seem to have a negative association with the number of episodes undertaken for primary and secondary religious activities, respectively.

Individual income levels (per month) are not found to be significantly influencing the decision of tourists in undertaking multiple episodes for primary and secondary religious activities. However, it is observed that with an increase in monthly income levels tourists, the probability of them taking numerous recreational and discretionary activity stops increases. As income increases, so also the spending limit and thus individual's involvement in shopping, taking fun rides, visiting gardens also increases. Furthermore, the effect of escorting person type (with whom have you traveled) on individual's stop making behavior across various activity types is explored. It is found that pilgrims/tourists visiting Kumbh with their family members have a higher likelihood of participating in religious (both primary and secondary) activities while those individuals accompanied by their friends have a higher inclination to get involved in recreational and discretionary activities. Besides, persons visiting on their own (alone) to Kumbh has no significant correlation with any of the activity types except that on recreational activity stops. The 'with whom' category is of interest to event planners and crowd managers in such mass gathering events as past studies have indicated 'with whom' is more positively associated with individuals safety perceptions (Gayathri et al., 2017; Illiyas et al., 2013) and hence their activity participation. Judging by the sign of the coefficients for members of family visiting Kumbh, it can be said that with an increase in the count of family members visiting Kumbh, their likelihood of taking numerous trips to participate in primary religious activities and discretionary activities exponentially increases. However, they limit their participation in recreational activities. As far as the effect of daily temperature on the stop-making behavior of tourists is concerned, Table 6 indicates that as the mercury (temperature) rises, it reduces tourist's participation in recreational and discretionary activities. A plausible explanation can be that as most of the recreational and discretionary activities at Kumbh Mela event are performed under the open sky; thus, as the daily temperature rises, the participation in these activities decreases.

Furthermore, the nature of relationship between the decision to participate in remaining activity types on the propensity of taking stops for a particular activity type (e.g., the effect of secondary religious, recreational, and discretionary activity types on the number of stops made during primary religious activity) is explored. The coefficients indicate that individuals who participate in primary religious activities are more likely to undertake secondary religious episodes and less likely to participate in discretionary activities. Next, it is observed that tourists who decide to participate in secondary religious or recreational or discretionary activities are most likely to include religious activity stops in their trip chain, which is a quite interesting finding.

\subsection{Planning implications}

Primarily, the planning process in a tourism/religious event consists of the following basic components as concluded by past studies (Inskeep, 1988; Risteskia et al., 2012):

- Places of attraction and the activities performed

- Accommodation facilities and related services

- Other facilities and services such as banking and money exchange, retail shopping, food outlets, tourist information, health care etc.

- transportation facilities and services

- Other infrastructure services such as water supply, electric power, waste disposal etc.

The present study mainly focuses on the first attribute of planning process at a religious event i.e. on the activity participation, trip chain, time spent and stop making propensities of visitors. Thus, based on the results presented in Tables 5 and 6 , this section discusses the implications of the research results for better planning of such religious events. Some of the socio-demographic variables appearing on the final models (both SEM and OL models) are discussed from a broad planning perspective.

From Table 5, it is seen that with an increase in age groups, the activity participation rate of pilgrims decreases (secondary religious and recreational activities) and hence the total time spent in these activities. So, planning must be done that encourages safe and secure routes inside the cordoned off region of Kumbh Mela for older age groups (irrespective of gender) for performing religious activities must be implemented as around 75 million devotees visited the Ujjain Kumbh Mela, 2016 with close to 10-15 million pilgrims taking holy dip on Shahi Snan days ("75 million attend Ujjain's Kumbh Mela - Matters India," n.d., "Ujjain: As Kumbh draws to a close, devotees throng Kshipra for 'shahi snan' | India News, The Indian Express," n.d.). This would reduce their fear of any mishaps so common in these mass gatherings. In this context, geospatial technology can be used to map geospatial distribution of temporary arrangements and facilities provided at Kumbh to avoid man-made stampedes and mishaps (Saha and Khare, 2020). Besides, as indicated by the SEM model, male members of a family are less likely to undertake multiple episodes (complex trip chains) in a religious context. In addition, the results suggest that home-makers have a higher participation rate in primary religious and recreational activities. Both the above statements clearly indicate female members are more inclined to participate in such religious 
gatherings. Thus, schemes that encourage female participation such as shorter queue time for females for prayers or worship, specific pedestrian routes for females, as well as stringent policies ensuring their safety would ensure a positive experience for females.

Table 6 indicates that with an increase in the count of family members visiting Kumbh, their likelihood of participation in recreational activities decreases. This trend is observed, perhaps due to the safety concerns among the family members at recreational sites where it is very often congested by a disorganized crowd, unlike inside temples where a disciplined queue system is followed. The event planners must carefully address such concerns among the visitors as in country like India the family ties and social bondage are generally strong. As a sugggestion, a map may be given showing location of ghats, temple locations and exits, basic amenities like toilet and drinking water and help desk that will facilitate pilgrims visiting with (or without) family in planning their visit (Saha and Khare, 2020). Else, bad experiences would lead to negative words of mouth (WOM) and pessimistic opinions and thus less footfall for these events (Verma and Sarangi, 2019). Finally, it is observed that for a unit increase in temperature, the odds of underataking higher no of stops for recretional and discretionary activities is 0.901 and 0.957 times lower (given the other variables are held constant in the model), respectively. The average temperature during the entire Kumbh Mela duration was $32.55{ }^{\circ} \mathrm{C}$ (as obtained in Table 2) with a peak temperature of $43^{\circ} \mathrm{C}$ which was on the higher side. So adequate sheds at minimal gaps (for resting of vsisitors) with clean drinking water facilities must be provided by the authorities at places of recreation and discretion. In addition as the authors have observed, the entire Kumbh mela region is covered by pilgrims through walking i.e. on an average 4-5 km walk distance in scorching heat ("75 million attend Ujjain's Kumbh Mela - Matters India," n.d.) so adequate information and signage boards for various facilities must be provided by authorities to guide the visitors. To sum it up, it can be said that the challenges faced in planning Kumbh Mela event for an anticipated influx and providing facilities and services to millions of pilgrims, was to ensure optimal resource deployment with assurance of a minimum desired level of facilities (be it temple worship or taking holy dip or participation in recreational activities) which should be both safe and accesible for all section of population.

\section{Conclusion}

For centuries, religious events of global importance have always attracted thousands of people to these destinations where they not only interact, socialize with a heterogeneous population but also participate in activities of religious and cultural importance. Moreover, these events happen over a short period in a constrained space. Such complexity associated with these events makes the preplanning of paramount importance to better plan and manage the influx of crowd. The benefits include not only avoiding congestion and overuse of particular locations but also in better management of logistics from a planning perspective. Moreover, to achieve these goals, the event planners and crowd managers need to have a better understanding of the socio-demographic characteristics of the target population, influence of climatic conditions, their likelihood of participating in various activities, and the number of tours they undertake during their stay. To study the association between these attributes of a religious event, the present article uses a set of empirical frameworks to gather meaningful results.

First of all, the present research uses a structural equation model (SEM) to explore the direct, indirect, and total effect of sociodemographic variables and climatic conditions (daily local temperature) on the travel pattern of tourists that consists of their total time spent, and trip chain type at Kumbh. The indirect effects are mediated by the activity participation variables, namely primary religious, secondary religious, and recreational activities. The SEM model offers very plausible indications concerning the impact of various socio-demographic variables on activity-travel behavior in a religious context. Some of the key findings of the SEM model are:

- Young (below the age of 35) and old (above 55 years) age visitors prefer participating in single activities (hence simple chains) while middle-aged individuals participate in multiple combinations of activities, and thus their trip pattern is complex.

- Male members are less likely to undertake multiple episodes (complex trip chains) in a religious context.

- The effect of occupational categories is, however, more pronounced for trip chain type than for total time spent.

- An increase in the members of a family visiting Kumbh decreases their overall time spent across various activities.

- Individuals who come in groups (either with families or friends) tend to decrease their propensity of taking complex trip chains

- Individuals who participate in primary and secondary religious activities tend to spend more time at Kumbh as compared to individuals who primarily visit for recreational purposes

Further, a series of ordered logit models were utilized to understand the propensity of individuals to undertake activity episodes at Kumbh Mela with the assumption that this propensity varied across individual traits of pilgrims. Some of the key findings that can dictate the formulation of policies in such mass gathering events are:

- Males have a lower tendency to take multiple stops for primary religious activities while they have a positive association with the number of discretionary activity stops being taken.

- Visitors with primary level of education are more inclined to indulge in recreational and discretionary activities while individuals who have completed intermediate or graduates are more likely to get involved in religious activities.

- Home-makers are more inclined to undertake primary religious episodes while students have a higher inclination towards recreational activities.

- An increase in the count of family members visiting Kumbh limits their participation in recreational activities.

- As the mercury (temperature) rises, it reduces tourist's participation in recreational and discretionary activities.

- Tourists who decide to participate in secondary religious or recreational or discretionary activities are most likely to include religious activity stops in their trip chain. 
Even though the results of this research offer vital insights regarding tourists' socio-demographic characteristics, transport planning, and activity participation in a religious setting, there are certain avenues to the current research which can be explored further. A joint model can be employed to simultaneously model the activity participation (multiple discrete choices) and time allocation (continuous variable) decisions. Future research would also be benefitted by applying random parameter models to reveal response heterogeneity and potential endogeneity issue. The study also did not consider the impacts of infrastructures, public amenities, and behavioral traits on the intention to participate in an activity that can be a scope for future research. The findings of the present study can be generalized by conducting similar activity-based at other religious settings or events of mass crowd gathering.

\section{Declaration of interest}

The work reported in this paper is part of the project titled "The Kumbh Mela Experiment: Measuring and Understanding the Dynamics of Mankind's largest crowd", funded by the Ministry of Electronics and Information Technology; Ministry of Communications; Government of India (MITO-0105), Netherlands Organization for Scientific Research, NWO (Project no. 629.002.202), and Robert Bosch Center for Cyber Physical Systems, Indian Institute of Science, Bangalore. (Grant No. RBCO001). The authors also express their gratitude towards Kumbh Mela administration and government of Madhya Pradesh, India for providing constant support and official permissions to carry out research work and establish Indo-Dutch collaboration research camp at Kumbh Mela-2016.

\section{Author contributions}

The authors confirm their contribution to the article as follows. Ashish Verma and Meghna Verma: Conceptualization, Data Collection, Supervision, Project administration, Funding acquisition; Punyabeet Sarangi and Vivek Yadav: Conceptualization, data curation, model building and interpretation, and article writing; Manoj Malayath: Supervision, article writing, reviewing and editing.

\section{Declaration of competing interest}

The authors have no conflict of interest.

\section{References}

75 million attend Ujjain's Kumbh Mela - Matters India [WWW Document], n.d. URL https://mattersindia.com/2016/05/75-million-attend-ujjains-kumbh-mela/ (accessed 11.11.20).

Ahmed, Q.A., Memish, Z.A., 2019. From the "Madding Crowd" to mass gatherings-religion, sport, culture and public health. Trav. Med. Infect. Dis. https://doi.org/ 10.1016/j.tmaid.2018.06.001.

Alejziak, W., 2013. Tourist activity inhibitors. Int. J. Cult. Tourism Hospit. Res. 7, 11-27. https://doi.org/10.1108/17506181311301327.

Amemiya, T., 1985. Advanced Econometrics., Advanced Econometrics. Harvard University Press. https://doi.org/10.2307/2554459.

Arentze, T.A., Timmermans, H.J.P., 2004. A learning-based transportation oriented simulation system. Transp. Res. Part B Methodol. 38, 613-633. https://doi.org/ 10.1016/j.trb.2002.10.001.

Arentze, T.A., Ettema, D., Timmermans, H.J.P., 2011. Estimating a model of dynamic activity generation based on one-day observations: method and results. Transp. Res. Part B Methodol. 45, 447-460. https://doi.org/10.1016/j.trb.2010.07.005.

Bhat, C.R., 1997. Work travel mode choice and number of non-work commute stops. Transp. Res. Part B Methodol. 31, 41-54. https://doi.org/10.1016/S0191-2615 (96)00016-1.

Bhat, C., 1999. An analysis of evening commute stop-making behavior using repeated choice observations from a multi-day survey. Transp. Res. Part B Methodol. 33, 495-510. https://doi.org/10.1016/S0191-2615(99)00003-X.

Bhat, C.R., Koppelman, F.S., 1999. A retrospective and prospective survey of time-use research. Transportation 26, 119-139. https://doi.org/10.1023/A: 1005196331393.

Bhat, C.R., Srinivasan, S., 2005. A multidimensional mixed ordered-response model for analyzing weekend activity participation. Transp. Res. Part B Methodol. 39, 255-278. https://doi.org/10.1016/j.trb.2004.04.002.

Bhat, C.R., Zhao, H., 2002. The spatial analysis of activity stop generation. Transp. Res. Part B Methodol. 36, 557-575. https://doi.org/10.1016/S0191-2615(01) 00019-4.

Biggest allocation — Kumbh gets a Central boost: Rs 100 cr to Madhya Pradesh | India News,The Indian Express [WWW Document], n.d. URL https://indianexpress. com/article/india/india-news-india/biggest-allocation-kumbh-gets-a-central-boost-rs-100-cr-to-madhya-pradesh-2758219/(accessed 5.31.20).

Buzinde, C.N., Kalavar, J.M., Kohli, N., Manuel-Navarrete, D., 2014. Emic understandings of Kumbh Mela pilgrimage experiences. Ann. Tourism Res. 49, 1-18. https://doi.org/10.1016/j.annals.2014.08.001.

Cao, X., Mokhtarian, P.L., Handy, S.L., 2008. Differentiating the influence of accessibility, attitudes, and demographics on stop participation and frequency during the evening commute. Environ. Plann. Plann. Des. 35, 431-442. https://doi.org/10.1068/b32056.

Chen, Y.-J., Akar, G., 2017. Using trip chaining and joint travel as mediating variables to explore the relationships among travel behavior, socio-demographics and urban form. J. Transp. Land Use 10. https://doi.org/10.5198/jtlu.2017.882.

Cheng, L., Chen, X., Yang, S., Wu, J., Yang, M., 2019. Structural equation models to analyze activity participation, trip generation, and mode choice of low-income commuters. Transp. Lett. 11, 341-349. https://doi.org/10.1080/19427867.2017.1364460.

Chu, Y.L., 2003. Empirical analysis of commute stop-making behavior. In: Transportation Research Record. National Research Council, pp. 106-113. https://doi.org/ 10.3141/1831-12.

Daisy, N.S., Millward, H., Liu, L., 2018. Trip chaining and tour mode choice of non-workers grouped by daily activity patterns. J. Transport Geogr. 69, 150-162. https://doi.org/10.1016/j.jtrangeo.2018.04.016.

Doherty, S.T., Mohammadian, A., 2011. The validity of using activity type to structure tour-based scheduling models. Transportation 38, 45-63. https://doi.org/ 10.1007/s11116-010-9285-x.

Gayathri, H., Aparna, P.M., Verma, A., 2017. A review of studies on understanding crowd dynamics in the context of crowd safety in mass religious gatherings. Int. J. Disaster Risk Reduct. 25, 82-91. https://doi.org/10.1016/j.ijdrr.2017.07.017.

Golob, T.F., 2000. A simultaneous model of household activity participation and trip chain generation. Transp. Res. Part B Methodol. 34, 355-376. https://doi.org/ 10.1016/S0191-2615(99)00028-4.

Golob, T.F., 2003. Structural equation modeling for travel behavior research. Transp. Res. Part B Methodol. 37, 1-25. https://doi.org/10.1016/S0191-2615(01) 00046-7. 
Golob, T.F., McNally, M.G., 1997. A model of activity participation and travel interactions between household heads. Transp. Res. Part B Methodol. 31, 177-194. https://doi.org/10.1016/S0191-2615(96)00027-6.

Hess, S., Palma, D., 2019. Apollo: a Flexible, Powerful and Customisable Freeware Package for Choice Model Estimation and Application.

Illiyas, F.T., Mani, S.K., Pradeepkumar, A.P., Mohan, K., 2013. Human stampedes during religious festivals: a comparative review of mass gathering emergencies in India. Int. J. Disaster Risk Reduct. https://doi.org/10.1016/j.ijdrr.2013.09.003.

Inskeep, E., 1988. Tourism planning: an emerging specialization. J. Am. Plann. Assoc. 54, 360-372. https://doi.org/10.1080/01944368808976497.

Kemperman, A., Borgers, A., Oppewal, H., Timmermans, H., 2003. Predicting the duration of theme park visitors' activities: an ordered logit model using conjoint choice data. J. Trav. Res. 41, 375-384. https://doi.org/10.1177/0047287503041004006.

Kitamura, R., 1988. An evaluation of activity-based travel analysis. Transportation. https://doi.org/10.1007/BF00167973.

Krizek, K.J., 2003. Neighborhood services, trip purpose, and tour-based travel. Transportation 30, 387-410. https://doi.org/10.1023/A:1024768007730.

Kun, L., Zhicai, J., Jie, T., 2009. Empirical analysis of commuter stop-making behavior based on ordered probit model. In: Proceedings - 2009 International Conference on Electronic Commerce and Business Intelligence. ECBI 2009, pp. 423-426. https://doi.org/10.1109/ECBI.2009.69.

Kuppam, A.R., Pendyala, R.M., 2001. A structural equations analysis of commuters. Transportation 28, 33-54.

LaMondia, J., Snell, T., Bhat, C.R., 2008. Tourism Travel within the European Union: the Impact of Personal Preferences and Perceptions on Vacation Destination and Travel Mode Choices.

Lew, A.A., McKercher, B., 2002. Trip destinations, gateways and itineraries: the example of Hongkong. Tourism Manag. 23, 609-621. https://doi.org/10.1016/ S0261-5177(02)00026-2.

Li, C.H., 2016. The performance of ML, DWLS, and ULS estimation with robust corrections in structural equation models with ordinal variables. Psychol. Methods 21, 369-387. https://doi.org/10.1037/met0000093.

Liu, C., Susilo, Y.O., Dharmowijoyo, D.B.E., 2018. Investigating intra-household interactions between individuals' time and space constraints. J. Transport Geogr. 73, 108-119. https://doi.org/10.1016/j.jtrangeo.2018.10.015.

Lu, X., Pas, E.I., 1997. A structural equations model of the relationships among socio-demographics, activity participation, and travel behavior. In: 76th Annual Meeting of Transportation Research Board. Washington DC.

Maat, K., Timmermans, H., 2006. Influence of land use on tour complexity. Transp. Res. Rec. J. Transp. Res. Board 234-241. https://doi.org/10.1177/ 0361198106197700127, 1977.

Maclean, K., 2008. Pilgrimage and Power: the Kumbh Mela in Allahabad, 1765-1954, Pilgrimage and Power: the Kumbh Mela in Allahabad, 1765-1954. Oxford University Press. https://doi.org/10.1093/acprof:oso/9780195338942.001.0001.

Manoj, M., Verma, A., 2015a. Activity-travel behaviour of non-workers from Bangalore City in India. Transp. Res. Part A Policy Pract 78, 400-424. https://doi.org/ 10.1016/j.tra.2015.06.006.

Manoj, M., Verma, A., 2015b. Activity-travel behaviour of non-workers belonging to different income group households in Bangalore, India. J. Transport Geogr. 49, 99-109. https://doi.org/10.1016/j.jtrangeo.2015.10.017.

Manoj, M., Verma, A., 2017. A structural equation model based analysis of non-workers' activity-travel behaviour from a city of a developing country. Transportation 44, 241-269. https://doi.org/10.1007/s11116-015-9636-8.

Masiero, L., Zoltan, J., 2013. Tourists intra-destination visits and transport mode: a bivariate probit model. Ann. Tourism Res. 43, 529-546. https://doi.org/10.1016/ j.annals.2013.05.014.

McKelvey, R.D., Zavoina, W., 1975. A statistical model for the analysis of ordinal level dependent variables. J. Math. Sociol. 4, 103-120. https://doi.org/10.1080/ 0022250X.1975.9989847.

Muthén, B., 1984. A general structural equation model with dichotomous, ordered categorical, and continuous latent variable indicators. Psychometrika 49, 115-132. https://doi.org/10.1007/BF02294210.

Nurul Habib, K., Miller, E., 2007. Modeling individuals' frequency and time allocation behavior for shopping activities considering household-level random effects. Transp. Res. Rec. J. Transp. Res. Board 78-87. https://doi.org/10.3141/1985-09, 1985.

Oberhagemann, D., Könnecke, R., Schneider, V., 2014. Effect of social groups on crowd dynamics: empirical findings and numerical simulations. In: Pedestrian and Evacuation Dynamics 2012. Springer International Publishing, pp. 1251-1258. https://doi.org/10.1007/978-3-319-02447-9_103.

Olsson, U., 1979. Maximum likelihood estimation of the polychoric correlation coefficient. Psychometrika 44, 443-460. https://doi.org/10.1007/BF02296207.

Pitombo, C.S., Kawamoto, E., Sousa, A.J., 2011. An exploratory analysis of relationships between socioeconomic, land use, activity participation variables and travel patterns. Transport Pol. 18, 347-357. https://doi.org/10.1016/j.tranpol.2010.10.010.

Primerano, F., Taylor, M.A.P., Pitaksringkarn, L., Tisato, P., 2008. Defining and understanding trip chaining behaviour. Transportation. https://doi.org/10.1007/ s11116-007-9134-8.

Puşcaşu, V., 2015. Religious tourism or pilgrimage? European Journal of Science and Theology.

R Core Team, 2020. R: A Language and Environment for Statistical Computing.

Raj, R., Griffin, K.A., 2015. Religious Tourism and Pilgrimage Management: an International Perspective. Cabi.

Raj, R., Griffin, K., Blackwell, R., 2015. Motivations for religious tourism, pilgrimage, festivals and events. In: Religious Tourism and Pilgrimage Management: an International Perspective. CAB International Wallingford, pp. 103-117.

Risteskia, M., Kocevskia, J., Arnaudov, K., 2012. Spatial planning and sustainable tourism as basis for developing competitive tourist destinations. Procedia - Soc. Behav. Sci. 44, 375-386. https://doi.org/10.1016/j.sbspro.2012.05.042.

Rosseel, Y., 2012. lavaan: an R package for structural equation modeling. J. Stat. Software 48, 1-36.

Saha, K., Khare, R., 2020. A geospatial approach to conserving cultural heritage tourism at Kumbh mela events in India. In: Urban Book Series. Springer, pp. 125-140. https://doi.org/10.1007/978-3-030-41905-9_9.

Simhastha Kumbh budget may rise to Rs 5,000 crore: MP Govt - The Economic Times [WWW Document], n.d. URL https://economictimes.indiatimes.com/news/ politics-and-nation/simhastha-kumbh-budget-may-rise-to-rs-5000-crore-mp-govt/articleshow/51070355.cms?from=mdr (accessed 5.31.20).

Simma, A., Axhausen, K.W., 2001. Within household allocation of travel - the case of upper Austria paper submitted for presentaion at the 80th Annual Meeting of the Transportation Research Board, Washington, D.C., January 2001. Transp. Res. Rec. J. Transp. Res. Board 69-75. https://doi.org/10.3929/ethz-a-010782581.

Smallwood, C.B., Beckley, L.E., Moore, S.A., 2012. An analysis of visitor movement patterns using travel networks in a large marine park, north-western Australia. Tourism Manag. 33, 517-528. https://doi.org/10.1016/j.tourman.2011.06.001.

Timmermans, H., van der Waerden, P., Alves, M., Polak, J., Ellis, S., Harvey, A.S., Kurose, S., Zandee, R., 2003. Spatial context and the complexity of daily travel patterns: an international comparison. J. Transport Geogr. 11, 37-46. https://doi.org/10.1016/S0966-6923(02)00050-9.

Ujjain: As Kumbh draws to a close, devotees throng Kshipra for 'shahi snan' | India News, The Indian Express [WWW Document], n.d. URL https://indianexpress.com/ article/india/india-news-india/ujjain-simhastha-humbh-mela-ends-kshipra-river-2812330/(accessed 6.1.20).

Verma, M., Sarangi, P., 2019. Modeling attributes of religious tourism: a study of Kumbh Mela, India. J. Conv. Event Tour. 20, 296-324. https://doi.org/10.1080/ 15470148.2019.1652124.

Verma, A., Verma, M., Rahul, T.M., Khurana, S., Rai, A., 2018. Acceptable trip distance for walking in mass religious gatherings-a case study of world's largest human gathering Kumbh Mela in Ujjain, India. Sustain. Cities Soc. 41, 505-512. https://doi.org/10.1016/j.scs.2018.06.010.

Weiss, A.A., 1997. Specification tests in ordered logit and probit models. Econom. Rev. 16, 361-391. https://doi.org/10.1080/07474939708800394.

Whitehead-Frei, C., Kockelman, K.M., 2010. Americans' time use. Transp. Res. Rec. J. Transp. Res. Board 2163, 32-44. https://doi.org/10.3141/2163-04.

Witt, S.F., Witt, C.A., 1995. Forecasting tourism demand: a review of empirical research. Int. J. Forecast. 11, 447-475. https://doi.org/10.1016/0169-2070(95) 00591-7.

WTO, 2007. A practical guide to tourism destination management, A practical guide to tourism destination management. https://doi.org/10.18111/9789284412433.

Xia, Y., Yang, Y., 2019. RMSEA, CFI, and TLI in structural equation modeling with ordered categorical data: the story they tell depends on the estimation methods. Behav. Res. Methods 51, 409-428. https://doi.org/10.3758/s13428-018-1055-2. 
Xia, J., Zeephongsekul, P., Packer, D., 2011. Spatial and temporal modelling of tourist movements using Semi-Markov processes. Tourism Manag. 32, 844-851. https://doi.org/10.1016/j.tourman.2010.07.009.

Yang, M., Wang, W., Ren, G., Fan, R., Qi, B., Chen, X., 2010. Structural equation model to analyze sociodemographics, activity participation, and trip chaining between household heads. Transp. Res. Rec. J. Transp. Res. Board 2157, 38-45. https://doi.org/10.3141/2157-05.

Yang, Y., Wong, K.K.F., Zhang, J., 2011. Determinants of length of stay for domestic tourists: case study of yixing. Asia Pac. J. Tourism Res. 16, 619-633. https://doi. org/10.1080/10941665.2011.610144.

Zoltan, J., McKercher, B., 2015. Analysing intra-destination movements and activity participation of tourists through destination card consumption. Tourism Geogr. 17, 19-35. https://doi.org/10.1080/14616688.2014.927523. 